\title{
Metastatic Carcinoma in the Adrenal Cortex
}

National Cancer Institute

\section{Source}

National Cancer Institute. Metastatic Carcinoma in the Adrenal Cortex. NCI Thesaurus. Code C27381.

A carcinoma that has spread to the adrenal cortex from an adjacent or distal anatomic site. 